\title{
Meningkatkan Kesejahteraan Perekonomian Masyarakat Melalui Kelompok Usaha Bersama (KUBE) Di Desa Batuyang Kecamatan Pringgabaya Kabupaten Lombok Timur
}

\author{
Immy Suci Rohyani ${ }^{1 *}$, Mulyana Hidayani ${ }^{2}$, Ratnah Hartinah ${ }^{3}$ \\ ${ }^{\text {I}}$ Fakultas Matematika Dan Ilmu Pengetahuan Alam, Universitas Mataram \\ ${ }^{2}$ Program Studi Peternakan, Universitas Mataram \\ ${ }^{3}$ Program Studi PPKn, Universitas Mataram
}

Article history

Received: 14-06-2020

Revised: 26-06-2020

Accepted: 07-07-2020

*Corresponding Author:

Immy Suci Rohyani,

Fakultas Matematika Dan Ilmu

Pengetahuan Alam, Universitas

Mataram, Mataram, Indonesia

Email: immy2@unram.ac.id
Abstract: West Nusa Tenggara is one of the provinces in Indonesia in which the poverty rate is still high. This condition requires the government to group the community in every village such that the community can be easily controlled and trained to enhance their skills. This group is known as KUBE. Batuyang is one of the villages which was effected by the Lombok earthquake in 2018. This condition causes an economic decline in the village. Approaches should be executed to improve the welfare of the community's economy through the KUBE program in Batuyang village. The efforts of the team to achieve these goals were identifying potentials, forming KUBE, and conducting counseling and training events. Based on the identification results, the team initiated a joint business group of Tobacco and Coffee. The counseling, training, and mentoring activities carried out by the team had a positive impact which is increasing the skills of the community, especially KUBE members, in processing, packaging, and marketing their products. As an outcome, they have a high selling value which is ultimately expected to improve their economy and welfare.

Keywords: skills; KUBE; tobacco; coffee

Abtrak: Nusa Tenggara Barat merupakan salah satu provinsi di Indonesia yang tingkat kemiskinannya terbilang cukup tinggi. Berdasarkan hal tersebut mengharuskan pemerintah untuk melakukan pengelompokan kepada masyarakat pada setiap desa, agar masyarakat mudah dikontrol dan dilatih untuk dapat memiliki keterampilan yang baik. Pembentukan kelompok ini sering dikenal dengan istilah Kelompok Usaha Bersama (KUBE). Desa Batuyang merupakan salah satu desa yang mengalami kerusakan akibat dari gempa bumi, kondisi ini menyebabkan penurunan ekonomi pada desa tersebut. Perlu adanya upaya peningkatan kesejahteraan perekonomian masyarakat melalui KUBE di Desa Batuyang. Upaya Tim pelaksana kegiatan pengabdian kepada masyarakat untuk mencapai tujuan tersebut adalah dengan melakukan identifikasi potensi, pembentukan kelompok usaha bersama kemudian melakukan penyuluhan dan pelatihan. Berdasarkan hasil identifikasi potensi KUBE Tembakau dan Kopi. Kegiatan penyuluhan, pelatihan dan pendampingan yang dilakuakan tim pengabdian masyarakat memberi dampak positif yaitu meningkatkannya keterampilan masyarakat khusunya anggaota KUBE dalam mengolah, mengemas dan memasarkan produnya sehingga memiliki nilai jual yang tinggi yang akhirnya diharapkan dapat meningkatakan perekonomian dan kesejahteraan masyarakat.

Kata Kunci: ketermpilan, KUBE, tembakau; kopi 


\section{PENDAHULUAN}

Nusa Tenggara Barat merupakan salah satu provinsi di Indonesia yang tingkat kemiskinannya terbilang cukup tinggi yakni sebanyak 735,62 ribu orang atau $14,63 \%$ dari total kependudukan. (Badan Pusat Statistik, 2018). Tingginya tingkat kemiskinan di NTB dapat terjadi karena tingkat pendidikan dan perekonomian masyarakat yang rendah, Kondisi ini mengharuskan pemerintah untuk memberikan perhatian kepada masyarakat pada setiap desa dengan melakukan pengelompokanpengelompokan agar mudah melakukan control untuk pengembangan, salah satunya melalui pembentukan Kelompok Usaha Bersama (KUBE).

Kelompok Usaha Bersama (KUBE) dibentuk dilandasi oleh filosofi “dari”, "oleh", dan "untuk" masyarakat. Artinya bahwa keberadaan suatu kelompok KUBE dimanapun (desa atau kota) adalah berasal dan berada di tengah-tengah masyarakat setempat dan peruntukannya untuk masyarakat (Departement Sosial RI, 2004). Menurut Sumodiningrat (2009) KUBE adalah warga atau keluarga binaan yang dibentuk melalui proses kegiatan pemberdayaan masyarakat untuk melaksanakan kegiatan kesejahteraan sosial dan usaha ekonomi dalam semangat kebersamaan sebagai sarana untuk meningkatkan taraf kesejahteraan sosialnya.

Kegitan pengabdian dilakukan di desa Batuyang merupakan salah satu desa yang terletak di kecamatan Pringgabaya Kabupaten Lombok Timur, yang terdiri dari 13 dusun. Batuyang termasuk desa yang mengalami kerusakan yang tergolong parah akibat dari musibah gemba bumi yang dialami masyarakat Lombok pada tahun 2018, sehingga menyebabkan penurunan ekonomi masyarakat yang selama ini dikenal dengan komoditas utamanya yaitu tembakau dan kopi. Kegiatan pengabdian ini bertujuan untuk mengembangkan perekonomian masyarakat dengan membuntuk kelompok usaha bersama (KUBE) untuk menghidupkan kembali perekonomian yang ada di Desa Batuyang dengan mengoptimalakan Sumberdaya yang ada.

Program yang dikembangkan oleh tim pengabdian masyarakat yaitu "Meningkatkan Kesejahteraan Perekonomian Masyarakat Melalui Kelompok Usaha Bersama (KUBE) Di Desa Batuyang Kecamatan Pringgabaya Kabupaten Lombok Timur". Hal ini bertujuan untuk membantu dan memberikan motivasi serta pendampingan ke Masyarakat Desa Batuyang terkait pemecahan masalah ekonomi yang belum dikelola dengan baik pasca musibah gempa yang melanda desa ini.

\section{METODE}

Pengabdian masyarakat yang dilakukan di desa Batuyang dengan program "meningkatkan Kesejahteraan Perekonomian Masyarakata Melalui Kelompok Usaha Bersama (KUBE)" menggunakan metode diantaranya adalah pertama Identifikasi potensi (obeservasi, wawancara) dalam hal ini tim pengabdian masyarakat melakukan observasi dan wawancara kepada masyarakat dan kepala desa tujuannya untuk mengetahui potensi apa saja yang ada di desa Batuyang. Kedua tim pengabdian masyarakat melakukan kegiatan FDG yakni tim pengabdian masyarakat mendiskusikan dengan masyarakat dan kepala desa untuk menentukan potensi unggulan yang akan dibentuk menjadi KUBE desa Batuyang. Ketiga, Sosialisasi, tim pengabdian masyarakat melakukan sosialisasi kepada masyarakat dan kepada desa serat jajarannya dengan tujuan untuk menjelaskan program yang akan dijalankan tim pengabdian masyarakat di desa Batuyang dengan cara ceramah dan diskusi. Keempat, Pembentukan KUBE, dalam hal ini tim pengabdian masyarakat membentuk kelompok usaha bersama berdasarkan persayaratan yang diberikan oleh pihak dinas. 
Kelima, Penyuluhan tentang KUBE, setelah kelompok terbentuk tim pengabdian masyarakat mengadakan penyuluhan tentang KUBE dengan tujuan membangun kesamaan persepsi diantara anggota dan memberi gambaran bagaimana mempertahankan KUBE agar tetap berjalan. Keenam, Pelatihan keterampilan berusaha, metode yang digunakan demonstasi (praktik langsung) dan diskusi, tujuannya meningkatkan kemampuan praktis berusaha yang disesuaikan dengan minat dan keterampilan peserta KUBE serta menumbuhkan rasa percaya diri peserta dalam dalam menghadapai permasalahan dan memulai usahanya. Ketujuh, Pendampingan metode diskusi intensif bertujuan untuk memastikan semua program yang sudah direncanakan dapat berjalan sesuai dengan yang diharapkan.

\section{HASIL DAN PEMBAHASAN}

Kegiatan pengabdian kepada masyarakat ini dimulai dengan melakukan identifikasi potensi yang ada di desa Batuyang. Berdasarkan hasil observasi dan wawancara potensi-potensi yang dimiliki oleh desa Batuyang ialah peternak, petani, nelayan, pedagang dan kreatifitas dalam membuat produk. Selanjutnya setelah melakukan identifikasi potensi, tim pengabdian masyarakat melakukan FDG dan selajutnya sosialisasi. Berdasarkan hasil diskusi yang dilakukan tim pengabdian masyarakat dengan masyarakat setempat dan kepala desa serta jajarannya potensi yang diangkat adalah pertanian berupa tanaman tembakau dan kopi.

Berdasarkan hasil FGD dan sosialisasi yang telah dilakukan maka dapat ditetapkan lokasi pembangunan KUBE berada di Dusun Batu Belek. Pemelihan lokasi ini ditetapkan berdasarkan informasi yang diperoleh dari setiap Kadus, Masyarakat dan Kepala Desa Batuyang. Selain itu, penetapan lokasi pembentukan KUBE berdasarkan hasil pertimbangan tim pengabdian masyarakat terkait potensi pengembangan dan keberlanjutan KUBE yang akan dibentuk. Dusun Batu Belek memiliki sumberdaya pertanian yaitu tembakau dan kopi. Kualitas tembakau di dusun ini sangat bagus, ditunjang dengan kemampuan masyarakat dalam mengolah dan meracik kopi sehingga menghasilkan kopi yang berkualitas dan cukup diminati oleh pasar.

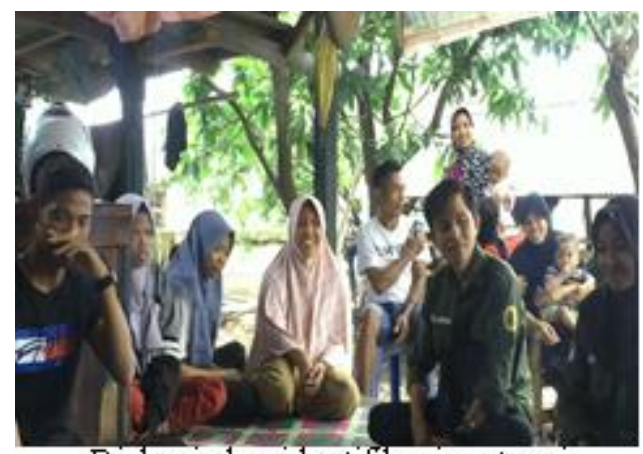

Diskusi dan identifikasi potensi

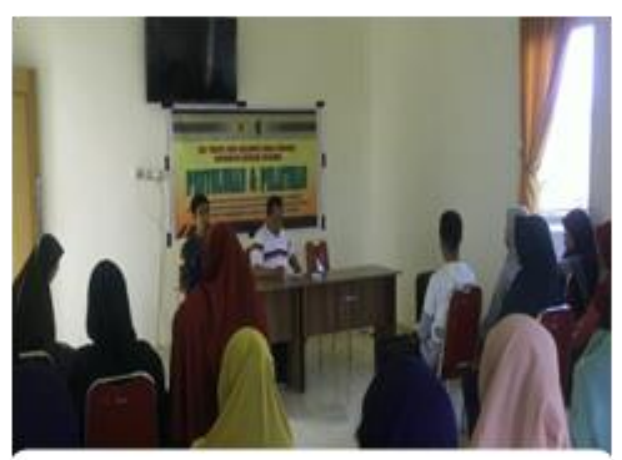

Kegiatan Penyuluhan

Setelah melakukan sosialisasi serta ditetapkannya lokasi maka kegiatan selanjutnya Pembentukan Kelompok Usaha Bersama. Penetapan kelompok dilakukan dengan cara meminta bantuan kepada salah satu masyarakat untuk menginformasikan dan mengumpulkan calon-calon anggota kemudian dilakukan pengumpulan berkas prasyarat untuk menjadi anggota KUBE berdasarkan ketetapan yang telah dibuat oleh Dinas. Kegiatan penseleksian dilakukan dengan cara mewawancarai peserta terkait motivasi mengikuti KUBE. 
Prasyarat yang ditetapkan oleh Dinas Sosial seperti masyarakat yang ingin bergabung harus termasuk anggota BDT, memiliki KKS atau PKH dan setiap kelompok harus terdiri dari 10 orang per kelompok. Prasyarat ini ditetapkan dengan tujuan agar masyarat yang tergolong tidak mampu atau berada pada garis kemiskinan dapat ditingkatkan kesejahteraan hidupnya dan juga agar bantuan-bantuan dari pemerintah tidak salah sasaran. Berdasarkan hasil pelaksanaan kegaiatan pembentukan kelompok diperoleh hasil berupa masing-masing anggota KUBE terdiri atas 10 orang. Kegiatan selanjutnya diadakannya penyuluhan tentang KUBE, dengan tujuan pelaksanaannya adalah untuk memberikan pemahaman kepada semua anggota KUBE tentang pentingnya membangun kelompok dalam menjalankan usaha serta memberikan arahan tentang cara mempertahankan kelompok agar tetap beroperasi. Menurut Padmanagara (2012) penyuluhan bertujuan membantu dan memfasilitasi masyarakat atau anggota KUBE beserta keluarganya untuk mencapai tingkat usaha yang lebih efisien/produktif, taraf kehidupan keluarga dan masyarakat yang lebih memuaskan melalui kegiatan-kegiatan yang terencana untuk mengembangkan pengertian, kemampuan, kecakapan mereka sendiri sehingga mengalami kemajuan ekonomi. Kegiatan penyuluhan ini diikuti dengan penuh antusias oleh anggota kelompok hingga selesai dan saat sesi tanya jawab hampir semua pesrrta aktif terlibat dalam diskusi.

Setelah penyuluhan di lanjutkan dengan pelatihan pengolahan dan pengemasan produk pangan yang dihasilkan dari KUBE. Pelatihan KUBE ini diadakan agar kelompok usaha yang ada mampu mengelola usaha mereka agar tetap berdiri dan berjalan sesuai dengan yang di harapkan. Kegiatan Pelatihan ini berfokus pada peningkatan keterampilan kelompok-kelompok yang telah dibentuk. Kegiatan pelatihan ini diikuti oleh sekitar

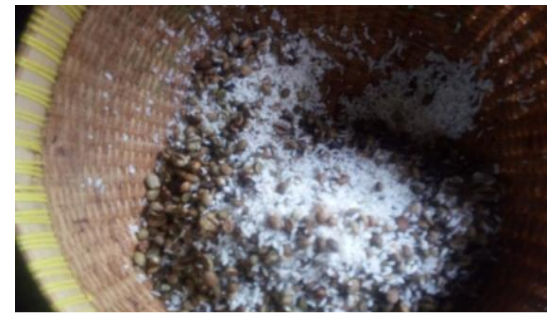

Pencampuran kopi dengan beras

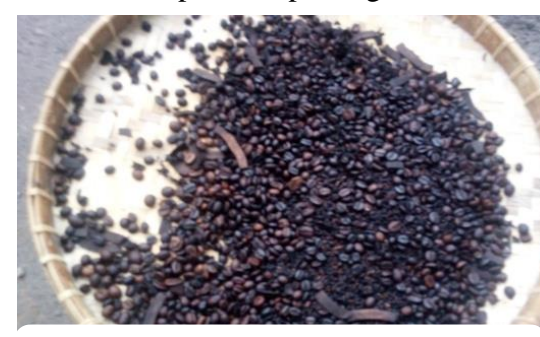

Bentuk kopi yang telah disangrai

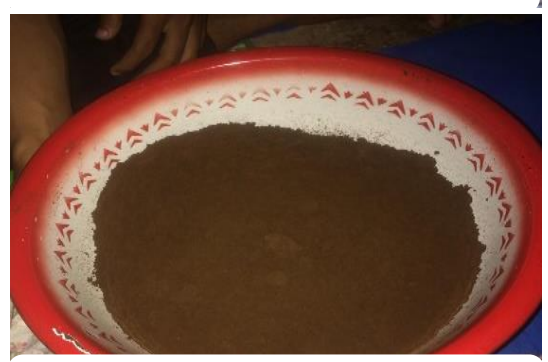

Kopi yang sudah di sangrai 30 anggota dari masing-masing kelompok dan beberapa masyarakat sekitar. Kegiatan pelatihan untuk dilaksanakan di dalam musholla dusun Batu Belek.

Materi pelatihan yang diberikan yaitu tentang pengolahan produk kopi. Pengolahan kopi itu mempunyai tujuan untuk meningkatkan produk olahan kopi sehingga layak untuk dikonsumsi dan memanfaatkan kopi agar memperoleh nilai jual yang tinggi dipasaran. Pengolahan kopi secara tepat akan mengurangi resiko terjadinya kerusakan, dapat memperpanjang umur simpannya, serta dapat meningkatkan nilai jualnya (Rukmana dan Yuniarsih, 2001). Proses pengolahan kopi tradisional ini menggunakan bahan-bahan berupa biji kopi, dan beras yang dibeli di pasar Suile. Tahapan dalam pembuatan bubuk kopi antara lain

> Biji kopi yang telah disediakan dicuci terlebih dahulu menggunakan air bersih, kemudian dicampurkan beras dengan perbandingan $1: 1$.

$>$ Memotong 1 buah kelapa dengan bentuk memanjang dan kemudian dicampurkan dengan kopi yang telah dicampur beras terlebih dahulu.

$>$ Kemudian bahan-bahan tersebut di sangrai berasamaan sedikit demi sedikit hingga semua bahan menghitam.

$>$ Tahap terakhir yakni, biji kopi tersebut di giling hingga halus setelah biji kopi tersebut dingin.

Selain materi pengolahan produk dilakukan juga pelatihan pengemasan produk yang langsung dipandu oleh Dinas Perindustrian dan Perdagangan. Pelatihan ini sangat penting dilakukan untuk meningkatkan nilai jual produk. Disamping itu Kemasan berperan sebagai wadah penyimpanan produk yang dapat melindungi produk selama proses pendistribusian. Kemasan juga merupakan identitas dari suatu produk. Kemasan 
juga dapat memperpanjang umur simpan suatu produk (Aminah, 2009). Pengemasan produk kopi dan tembakau diupayakan mengguakan produk yang ramah lingkungan terbuat dari bahan alam seperti ketas yang aman dan tidak membahayakan kesehatan, produk di kemas menggunakan kemasan jadi yang mudah didapatkan di masyarakat, produk kemasan juga harus memperhatikan nilai estetika dengan memperhatikan gradasi warna dan loga sehingga menarik minat pembeli

Selain melakukan kegiatan pelatihan dilakukan kegiatan pendampingan masyarakat, dalam bentuk pemasaran produk dan pembuatan proposal usaha. Pemasaran dilakukan dengan cara langsung maupun tidak langsung. Pemasaran secara langsung dilakukan di jalan udaya ketika acara Car Free Day (COD) berlangsung. Kegiatan pemasaran ini dilakukan dengan cara membuat stand atau tempat promosi di jalan Udayana, kemudia menawarkan produk yang dihasilkan ke setiap masyarakat yang melewati lokasi tersebut. Selain dengan pemasaran langsung, kami juga melakukan pemasaran tidak langsung melalui media sosial dengan cara membuat postingan di akun media sosial seperti instagram dan facebook agar produk yang dihasilkan dapat dilihat oleh masyarakat yang lebih luas.

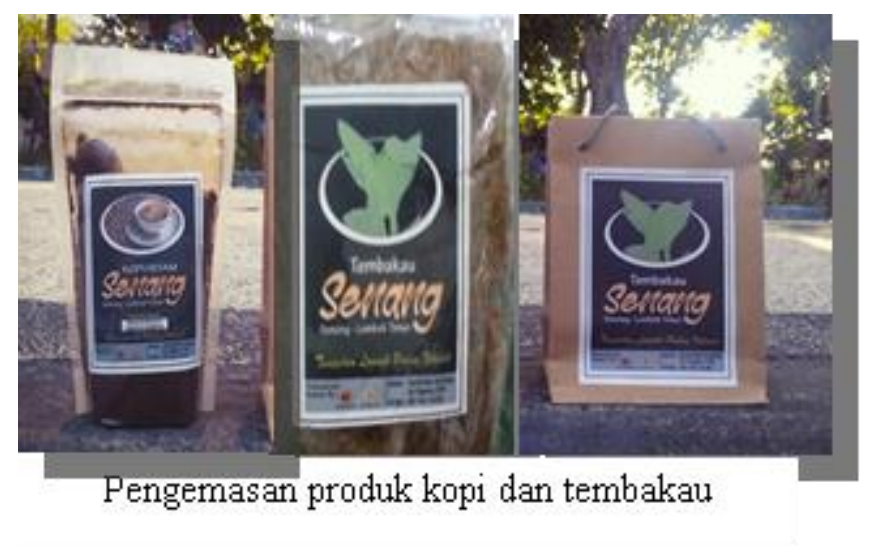

Pemasaran dengan cara langsung dan tidak langsung ini memberi dampak positif harga jual bisa lebih tinggi dan permintaan pasaran juga semakin meningkat. Diharapkan melalui perubahan cara pandang masyarakat dalam mengolah, mengemas dan memasarkan produknya diharapkan adanya perubahan peningkatan perekonomian masyarakat. Masyarakat yang biasanya mengolah kopi hanya untuk kebutuhan pribadi atau tidak pernah menjualnya karena harga jual yang rendah, tetapi setelah di bantu oleh tim pengabdian masyarakat untuk mengasah keterampilan pengolahan, pengemasan dan pemasaran kopi, masyarakat mendapat keuntungan sebesar 200 ribu rupiah untuk sekali pembuatan yang awalnya tidak mendapat keuntungan. Produk KUBE tembakau juga mengalamai peningkatan harga jual yang cukup signifikan semula harga jula tembakau Rp 250.000/tumpi setelah dikemas dan dipromosikan dengan pemasaran yang baik harga jual menjadi Rp 350.000/tumpi.

\section{KESIMPULAN DAN SARAN}

Kegiatan Pengabdian Kepada Masyarakat dengan Program Meningkatkan Kesejahteraan Perekonomian Masyarakat Melalui Kelompok Usaha Bersama (KUBE) di Desa Batuyang berjalan baik dan lancar. Penyuluhan, pelatihan dan pendampingan yang diberikan telah berhasil menstimulasi peserta untuk bersama-sama mengembangkan usahanya dan meningkatkan kualitas produknya melalui kelompok usaha bersama . Kegiatan ini juga telah berhasil meningkatkan nilai jual produk yang diharapkan dapat berimbas pada peningkatan perekonomian dan kesejahteraan masyarakat yang terdampak akibat gempa. 


\section{Ucapan Terima Kasih}

Segenap tim pengabdian masyarakat dengan ini mengucapkan terimakasih banyak kepada LPPM Universitas Mataram yang telah memberikan kami kesempatan untuk melakukan kegiatan pengabdian kepada Masyarakat. Ucapan Terimakasih kepada Kepala Desa dan Masyarakat Desa Batuyang atas dukungan dan kerja samanya dalam menjalankan program Meningkatkan Kesejahteraan Perekonomian Masyarakat Melalui Kelompok Usaha Bersama (KUBE).

\section{DAFTAR PUSTAKA}

Aminah, M. S., dan Rinasusanti, S. 2009. Meraup Duit Dari Barang Seken. Puspa Swara. Depok Badan Pusat Statistik. 2018. Provinsi Nusa Tenggara Barat dalam Angka 2018. BPS Nusa Tenggara Barat ; Mataram

Departement Sosial RI. 2004. Pengembangan Usaha Ekonomi Produktif Fakir Miskin Melalui Kelompok Usaha Bersama Dan Lembaga Keuangan Mikro.Jakarta: Departement Sosial RI. Direktorat Jenderal Bantuan Jaminan Sosial Dan Direktorat. Bantuan Fakir Miskin.

Padmanagara. 2012. Bapak Penyuluhan Pertanian Pengabdi Petani Sepanjang Hayat, Cet.1. Jakarta: PT Duta Karya Swasta. Rukmana dan Yuniarsih. 2001. Aneka Olahan Ubi Kayu. Yogyakarta : Kanisius. Saji, 2002. Resep Aneka makanan

Sumodiningrat, Gunawan.2009.Mewujudkan Kesejahteraan Bangsa.Elex Media Komputindo.Jakarta.

Talikanews. 2019. Angka Kemiskinan di NTB 2019 Menurun 0,07\%.

https://www.talikanews.com/2019/07/15/angka-kemiskinan-di-ntb-2019-menurun-007persen/. Diakses pada Senin, 9 Desember 2019 